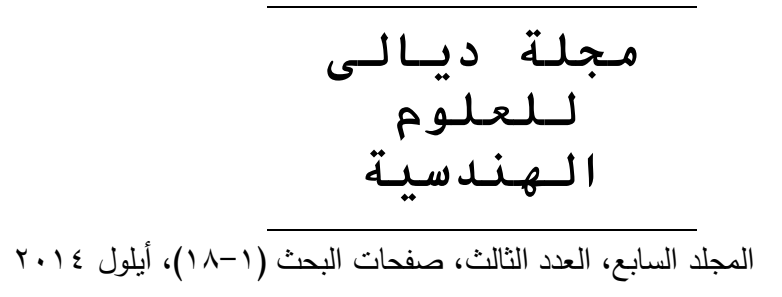

\title{
تقييم سمك الطبقة التالفة لنماذج خرسانية مسلحة معرضة للحريق
}

\author{
صافي مهدي عليوي

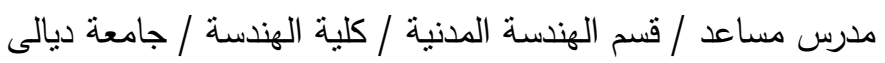

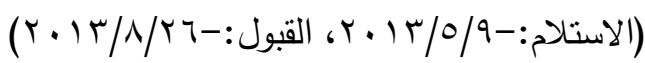

الخلاصة

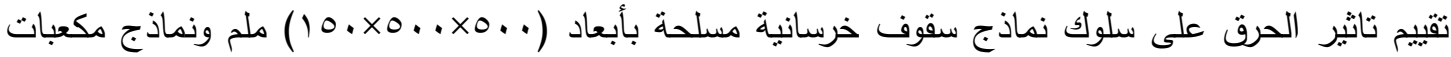

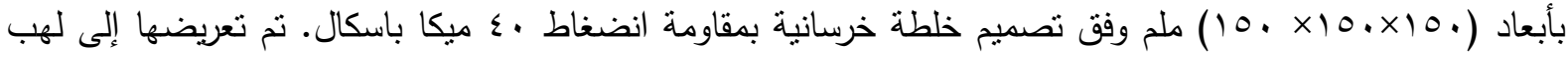

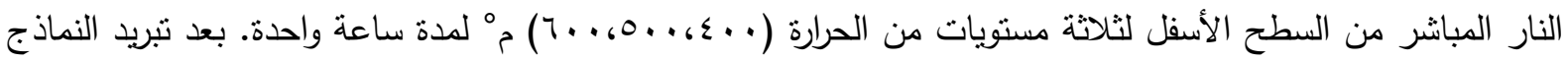

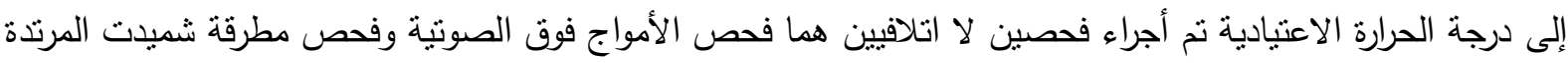

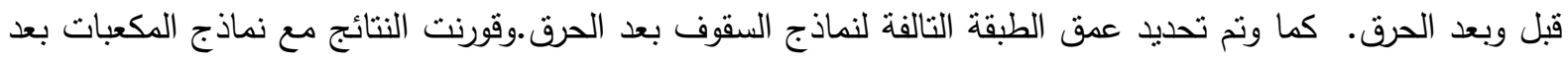

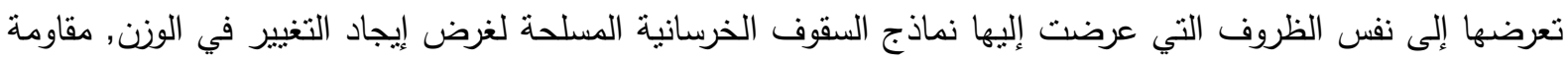

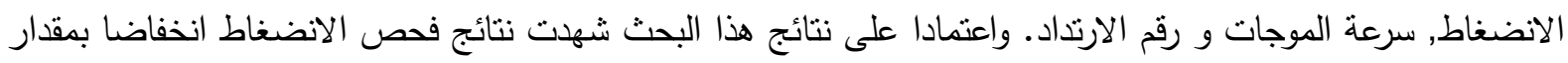

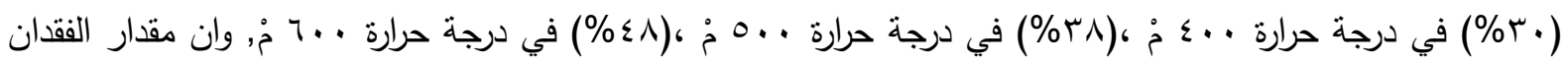

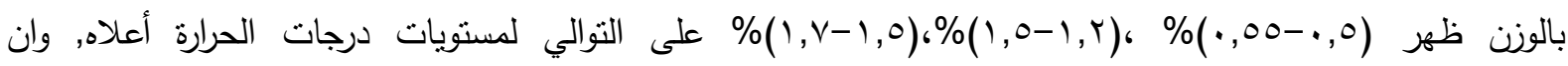

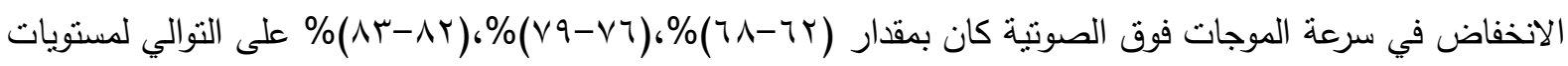

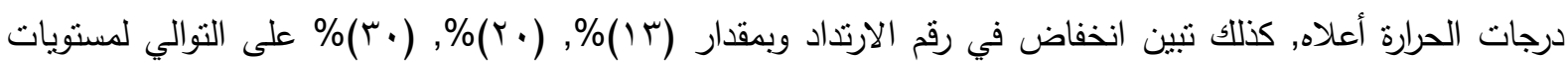
درجات الحرارة أعلاه.

مفاتيح الكلمات: نماذج خرسانية، درجات الحرارة العالية، فحص الانضغاط، الفحوص اللااتلافية.

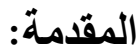

تعنبرالخرسانة من المواد الإنشائية الغير قابلة للاحتراق ومقاومة لانتقال الحرارة كونها ذات توصيلية حرارية ضعيفة نسيباً على الرغم من فقدانها للمقاومة عند ارتفاع درجة الحرارة واحتمال تحطمها الا انها تعتبر واقياً جيداً لحديد التسليح حيث اعطت العديد من المدونات والمواصفات محددات لسمك الغطاء الخرساني لاعطاء مقاومة للحريق لأطول فترة ممكنة.

قام الباحث حمدي الديداموني وآخرون (1) بدراسة تأثنر الإضافات البوزولانية على مقاومة الخرسانة لدرجات

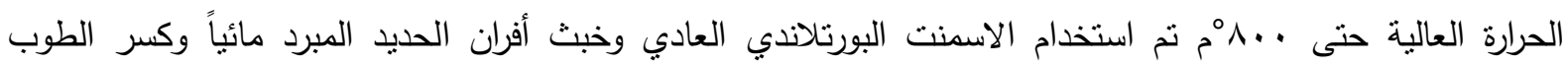

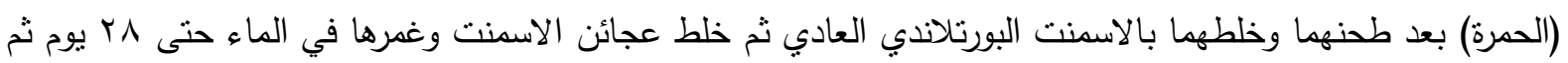


تعرضها لدرجات حرارة حتى . . ^م لمدة ثلاث ساعات وتركها تبرد في الفرن حتى درجة حرارة الغرفة أوضحت النتائج إن

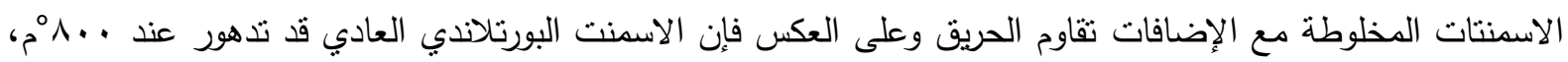

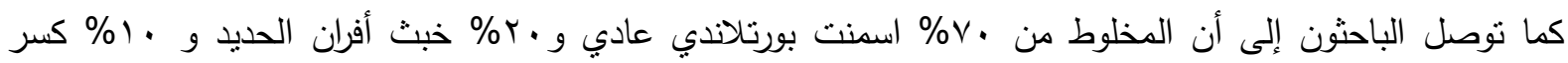
الطوب الطفلى أعطى أعلى مقاومة للحريق حتى . . ^مّ أي انه نسبياً يمكن أن يقاوم تدهور الخرسانة في المباني

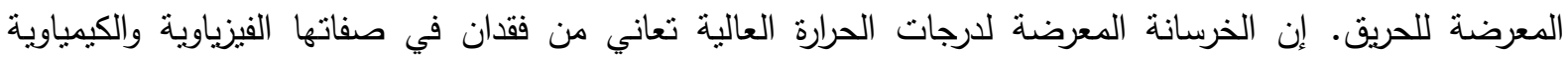

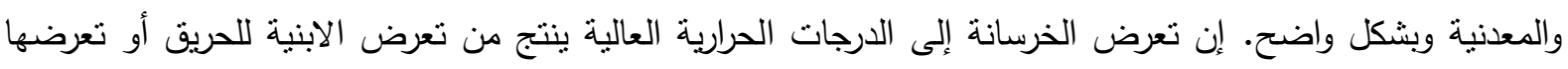

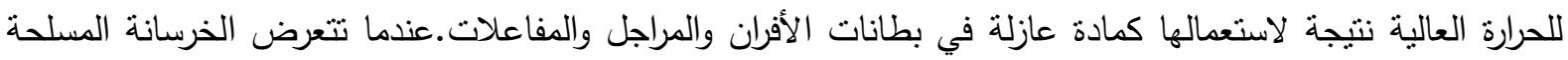
لدرجات حرارة عالية (أثناء الحريق) تتعدى . .بّم فأنها تفقد مقاومتها للضغط بسرعة ويفقد حديد التسليح نصف مقاومته

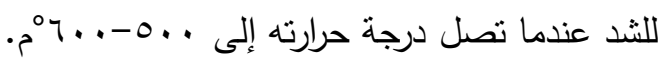

نشر الباحث (Zoldener) (Y) عام (YYI (1))، دراسة عن الخصائص الحرارية لخرسانة عالية المقاومة، حيث نم تثبيت عدد من العلقات الرياضية لهذه الخصائص كدالة لدرجة الحرارة، درس خصائص التوصيلية الحرارية والحرارة النوعية (Thermal Conductivity) الوزن للخرسانة، نم اخذ أربع مزجات خرسانية، هي مزجة خرسانية اعتيادية حاوية على ركام سلبلوزي وأخرى حاوية على والى ركام كاربوني (Carbnate Aggregate) ومزجة خرسانية مسلحة بالألياف الفولاذية وحاوية على ركام سليلوزي ومنلاهيا

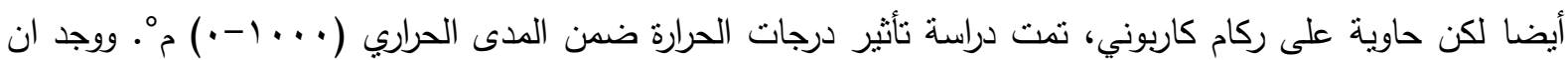

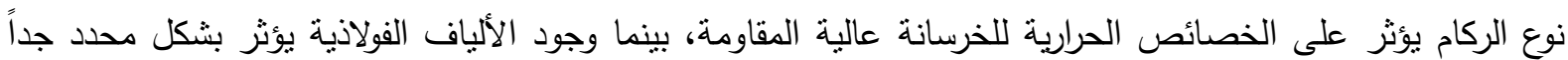
على الخصائص الحرارية للخرسانة. درست Essa (r) في 1999 نأثثر الحريق بلهب النار على بعض الخواص الميكانيكية للخرسانة وهي مقاومة

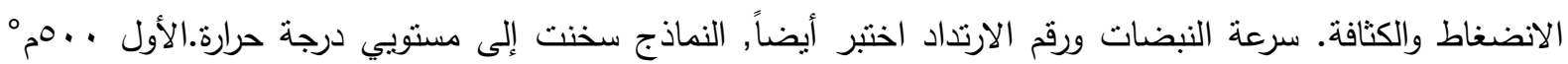

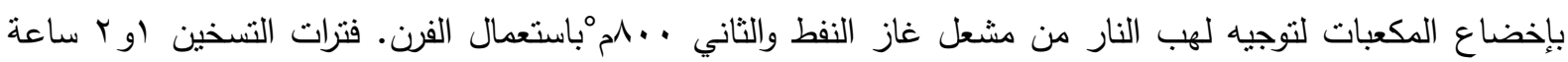

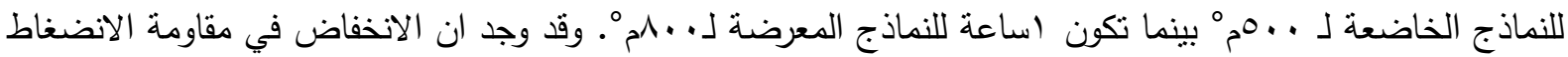

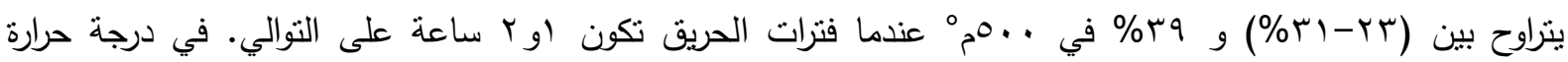
\% من المقاومة الأصلية وكذلك وجد ان الانخفاض في الكثافة يتراوح بين

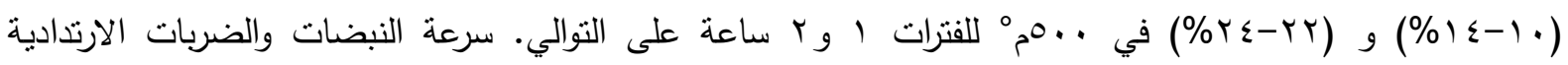

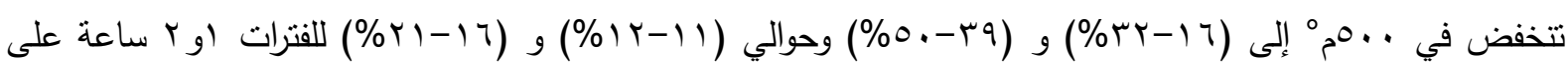

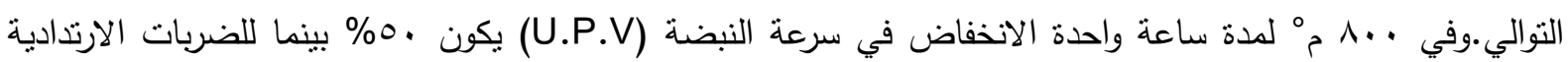

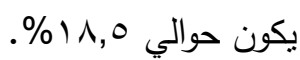

فقد درس الباحث (Devenny) (ع) عام (•191) تأثثر الحرارة العالية على مقاومة الانضغاط للخرسانة

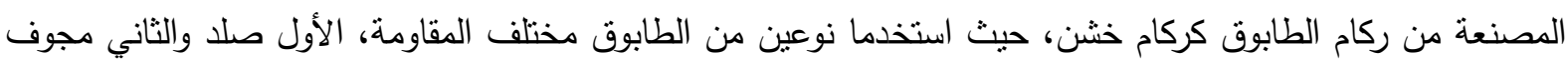
سحق للحصول على ركام خشن، تمت دراسة ثلاث مجاميع من المزجات الخرسانية، المجموعة الأولى ضمن مزجات خرسانية متوسطة المقاومة والمجموعة الثانية مزجات عالية المقاومة أما المجموعة الثالثة فضمن مزجات خرسانية دماتية مقصودة الهواء اضيف إليها مضاف الهواء المقصود بنسبة (\%\%)، كل مجموعة تضمنت ثناث مزجات، المزجة الأولى استخدم فيها ركام الطابوق الصلد والمزجة الثانية استخدم فيها ركام الطابوق المجوف أما المزجة الثالثة ولغرض المقاف الثارنة استخدم

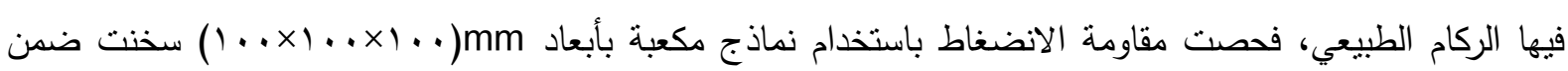




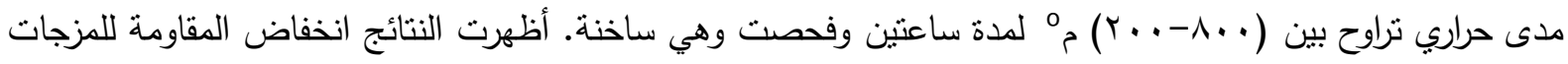

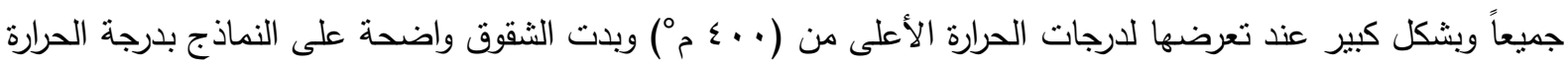
( . . م م)، وهو المزجات المتكونة من ركام الطابوق أظهرت أداء أفضل من الخرسانة الاعتيادية عند درجات الحرارة العالية، كما ان إضافة الهواء المقصود لم يحسن من مقاومة المزجات عند درجات الحرارة العالية. أجرى الباحث chung (7) عام (910 (1) دراسة على تأثثر الحرارة العالية في الخصائص الميكانيكية للخرسانة والخصائص التي يمكن الحصول عليها من طرائق الفحص غير الاتلافية (Non-Destructive Methods) وقد استخدم

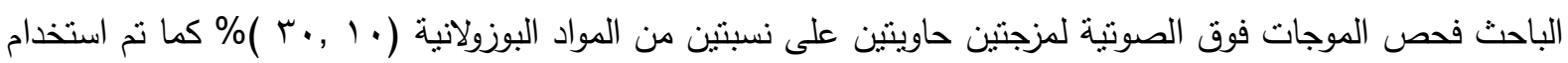

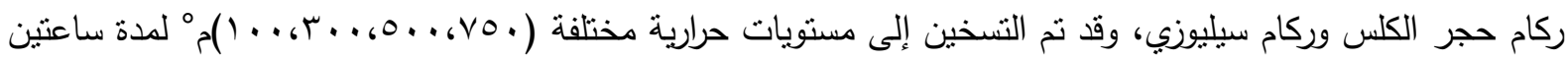
دون أي حمل مسلط في أثناء التسخين، بعد انتهاء العمر المقدر ثنلاث سنوات، وتم إجراء الفحوصات اللازمة، رأى الباحث ان الخصائص المنبقية للخرسانة تعنمد بشكل كبير على الركام ونوع المادة الرابطة.

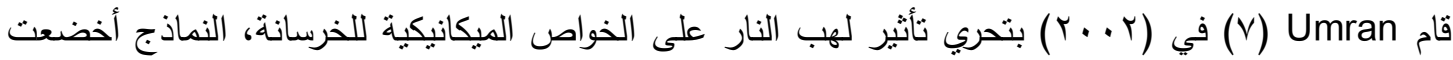

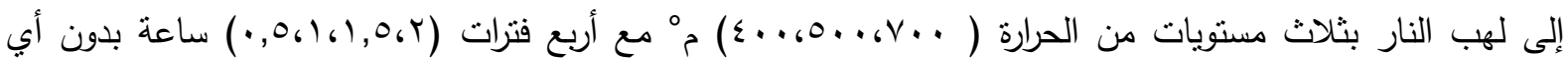
أحمال إضافية أثناء التسخين. النماذج سُخنت وبُردت تحت نفس النظام واختبرت بعد التعرض للهب في أعمار

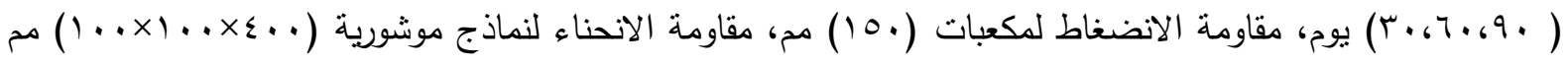

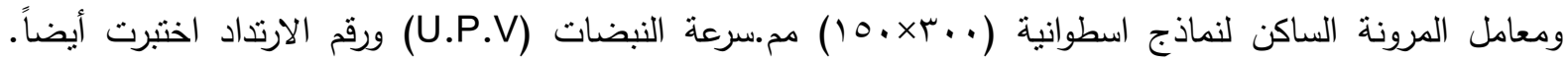

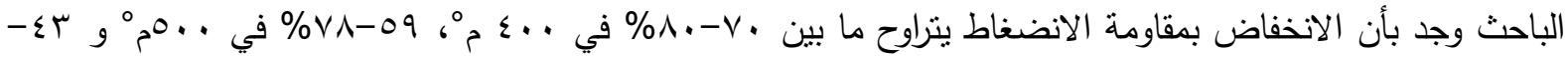

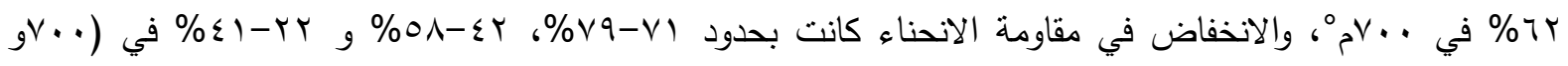

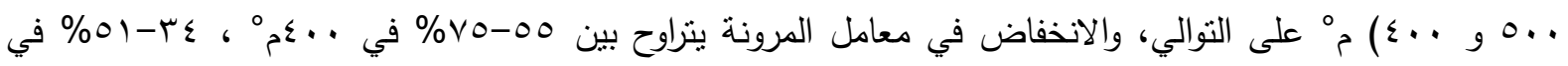

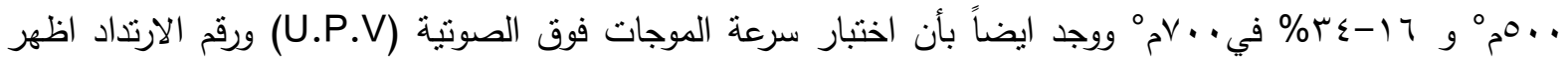

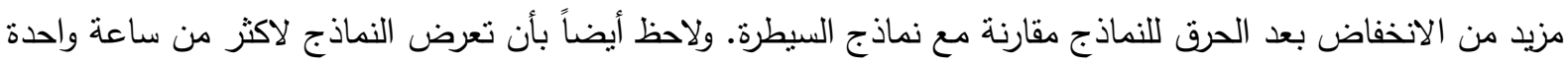
كان له تأثير هام على مقاومة الانضغاط المنتقية.

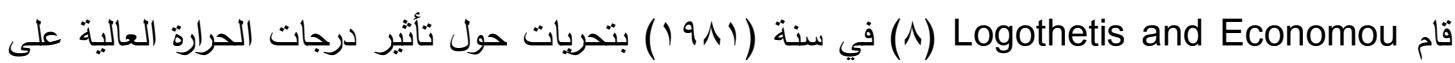
خواص الخرسانة باستخدام طرق غير اتلافية مثل مطرقة الارتداد وسرعة النبضات. سلسلتين من النماذج الخرسانية

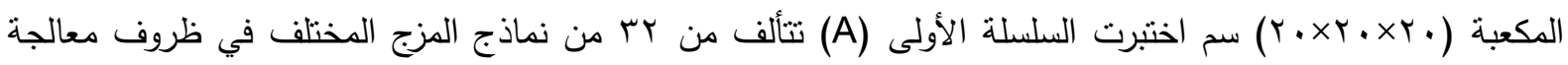

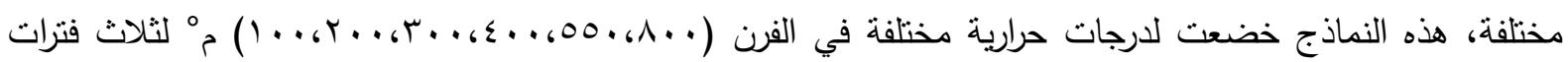

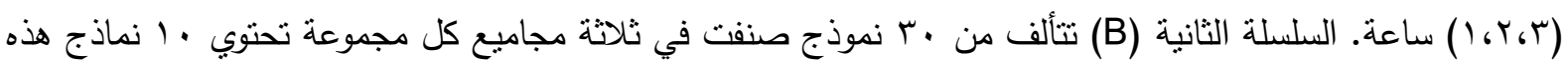

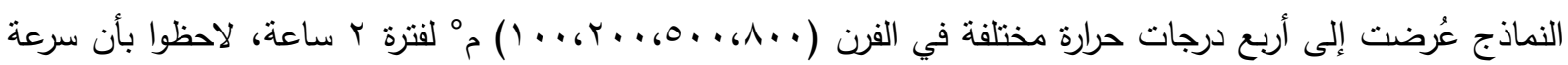

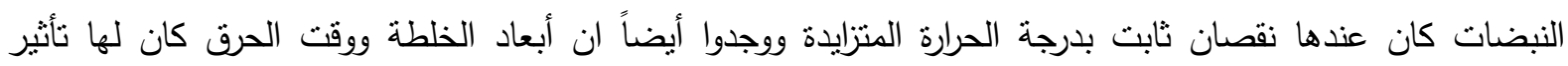

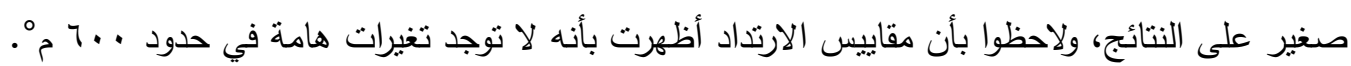
نشر Chung and law (9) عام (910 (1) دراسة أخرى لتقييم ضرر النار على الخرسانة. النماذج موشورات

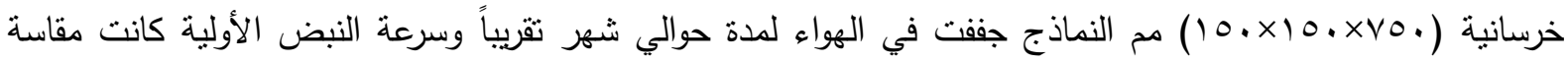

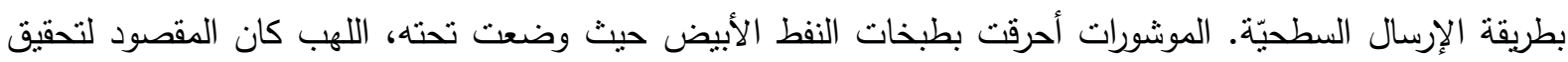
شرط التشخين في نار فعلية، كثافة اللهب عُدِلت لرفع درجات حرارة النموذج بعدما وصلت درجة الحرارة درجة الحرق

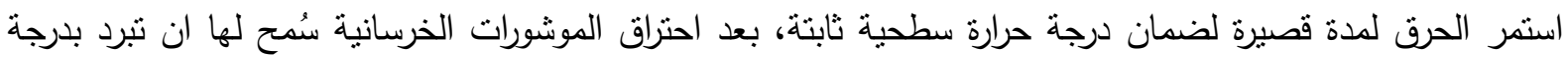




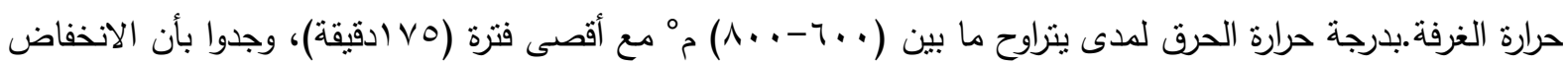
بسرعة النبضة كان ما بين سب-00\% من القيمة الأولية.

\section{طريقة العمل : - م}

في هذا الجزء سوف ينت توضيح تفاصيل المواد المستخدمة في الخلطة الخرسانية وكذلك نوعية المواد المستخدمة في الخلط منل وصف خواص الركام الخشن والناعم (Fine and coarse) والماء والاسمنت وكذللك عرض مواصفات الخلطة الخرسانية.كذللك يتضمن وصف صب مكعبات بقياس (10 (10 10.10) ملم ويتضمن وصف عملية حرق النماذج (cube and Slab) والأدوات المستخدمة لهذا الغرض.

\section{1- الخلطة المستخدمة في البحث}

تم تصميم الخلطة الخرسانية على مقاومة ــ ميكا باسكال هذه النسب هي للنماذج على شكل مكعبات بابعاد

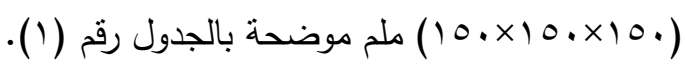

r - مواصفات المواد المستخدمة في الخلطة:

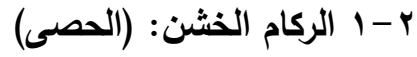

ان المكونات الرئيسية للخرسانة هو الركام والذي يشكل حوالي (†0\%) من الخرسانة وقد استخدم في هذا البحث نوع واحد من الركام الذي استخدم في خرسانة مشاريع جامعة ديالى، وهو الركام الخشن مقلع الصدور الذي يقع في

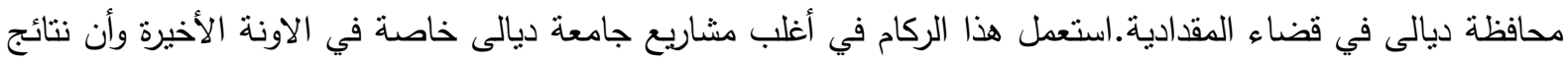

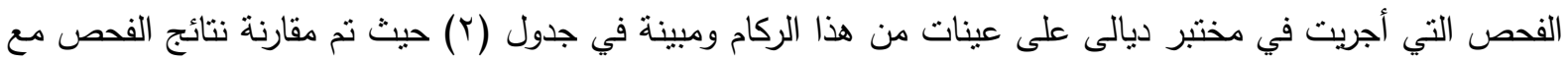
حدود المواصفة القياسية البريطانية (رقم ^) علماً قد تم غسل الركام قبل استعماله في المختبر واستخدم هذا النوع في

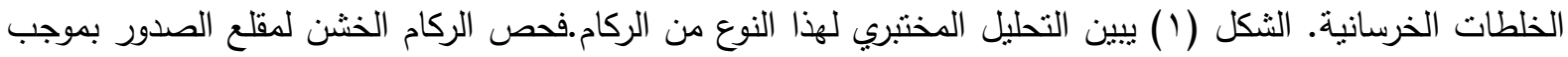

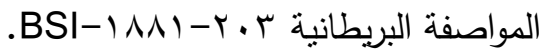

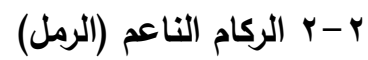

يتم تجهيز هذا النوع من الركام من مقلع الصدور الذي يقع شمال محافظة ديالى في قضاء المقدادية. استعمل هذا الركام في اغلب مشاريع جامعة ديالى ايضاً وخاصة في الفترة الأخيرة، ان نتائج الفحوصات المختبرية الني اجريت على عينات من هذا الركام كانت بموجب المواصفة البريطانية رقم (^).الجدول رقم (r) يوضح التحليل المنخلي لرمل مقلع الصدور والنسبة المئوية للمراد الناعمة والكبريتات والثكل(r) يبين التحليل المنخلي لهذا النوع من الركام.

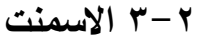

هي المادة التي تمتلك خواص تماسكية وتلاصقية بوجود الماء وهذه الخواص تجعل الاسمنت قادر على ربط الاجزاء المعدنية مع بضعها البعض وتحوله إلى وحدة كاملة ومتراصة وقد نم اختيار اسمنت نوع (طاسلوجة) وهو سمنت بورتلاندي اعتيادي ذو النتائج في جدول رقم(؟).

r r r r ب ماء الخلط 
إن الماء المستخدم لعمل الخلطات الخرسانية التجريبية هو الماء الصالح للثرب كما استخدم نفس الماء للمعالجة

r- تحضير نماذج الخلطات:

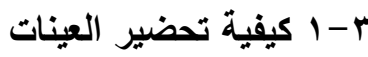

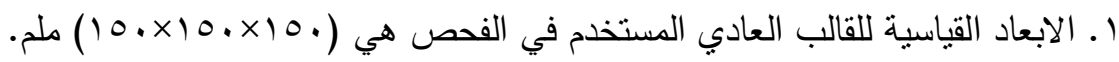
أما الأبعاد للنماذج الأخرى التي على شكل شريحة من سقف (slab) هي (0×0×0 (10) سم. r. القوالب مصنوعة من الحديد وذات تركيب يسمح برفع المكعب الخرساني بعد الصب دون حدوث أي ضرر فيه. ولقد تم تصنيع هذه القوالب في الاسواق المحلية وحسب المواصفات المطلوبة. r. اجزاء (زوايا) القالب متراصة مع بضها البعض وذللك لعدم تسرب الماء خلال عملية ملئ القالب ورصه. r-r r r عملية صب القوالب:

تملأ القوالب بالخرسانة بعد طلي القالب بطبقة من الزيت لـنع التصاق الخرسانة بالقالب عند رفعها.يتم صب الخرسانة في النموذج على شكل ثلاث طبقات كل طبقة (•0) ملم وترص كل طبقة بواسطة قضيب معدني بـ (مساضربة) موزعة بشكل منتظم لكي لا يحدث انعزال بالخرسانة بعد ذلك يتم اضافة التلث الثاني (•مملم) وترص كما مبينة في الحالة

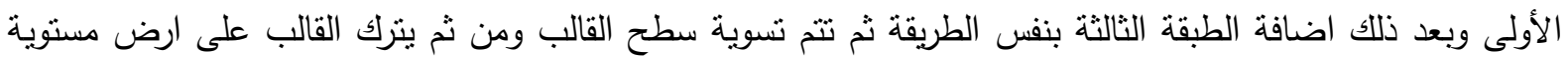

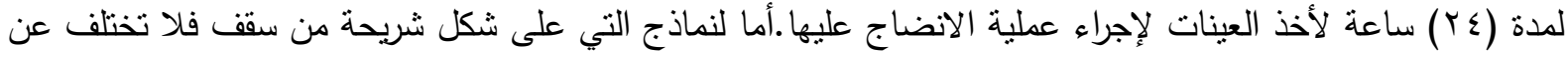

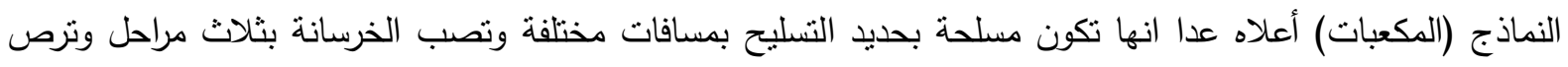
في كل مرحلة بـ هVاضربة ويتم تسوية سطح القالب ويتم خزن النماذج لمدة ء كاساعة بالمختبر وتغطى بطبقة من النايلون لمنع تبخر الماء من سطح الخرسانة بعدها تؤخذ لإجراء عملية الانضاج. r-r - ب طريقة معالجة المكعبات تم في كل مرة صب 1 مكعبات صغيرة حيث بعدها نم تعليم النماذج برموز واضحة ثم توضع النماذج في

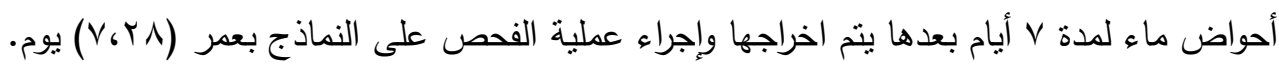

\section{ع - الفحوصات المختبرية}

ع - ا فحص الموجات فوق الصوتية جهاز معروف باسم (V-Metrec Mark III)

تعتبر فحوصات الموجات الفوق صوتية من أهم الفحوص الغير اتلافية وقدمها من حيث برجع استخدامها الأول إلى أواخر الثلاثينات على يد بعض العلماء منل (Powers) و (Thomson) في هذه الطريقة يتم إحداث نبضات عبارة عن موجات فوق الصوتية لتسري خلال الجزء المختبر ويتم تعيين زمن انتقالها، حيث وجد ان سرعة النبضات خلد جسم

صلب يعتمد على كثافة المادة المختبرة وخواص المرونة لها (ه). طريقة إجراء الاختبار: 1. يتطلب إجراء هذا الاختبار كفاءة عالية. 
r أستخدام أجهزة لإنتاج نبضات مناسبة مع المارة.

r. يتم ضبط الجهاز مع جزء المعيارة المرفق مع الجهاز قبل بدء الاختبار على العينة.

ء. يتم قياس المسافة التي تسيرها النبضات (path length) بدقة (أي طول السير).

ه. يوضع المرسل (Transmitter) والمستقبل (receiver) على العينة وأن يكون الاتصال تام بين سطحي المرسل والمستقبل وسطح العينة (يستخدم لهذا الغرض الثحم والجليسرين أو الصابون السائل).

آ. عند وضع المرسل والمستقبل على العينة يستمر هذا الوضع حتى تتبت القراءة وإذا تأرجحت النتائج بين القراءتين يؤخذ المتوسط.

V. يكون الرقم معبراً عن الوقت لسريان النبضات خلال الجزء المختبر . ^. الآتي

$\mathrm{V}=\mathrm{L} / \mathrm{T}$

$L=$ Length

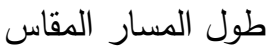

T=Transit Time

زمن انتقال الموجة

9. يستخدم منحني المعيار الخاص لإيجاد مقاومة ضغط المكعب المكافئ وقد وضع هذا المنحني على أساس اختبار

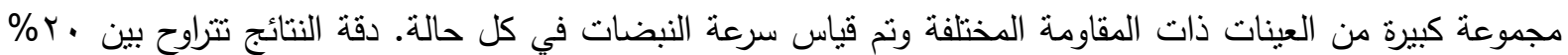
من القيمة الفعلية لمقاومة الضغط. وضع المرسل والمستقبل: توجد طريقتين لوضع المرسل والمستقبل: ا . في اتجاهين متضادين (قياس مباشر Direct Transmission).

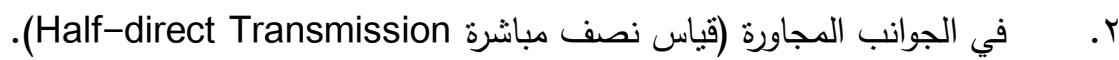
تستخدم الطريقة الأولى في حالة إمكانية وضع المرسل والمستقبل بهذا الوضع ويمتل أفضل وضع. أما الطريقة الثانية فيتم الانتقال على طول السطح وذلك في حالة إمكانية الوصول إلى سطح واحد فقط من العنصر المختبر وفي هذه

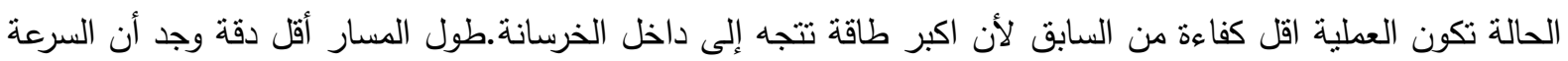

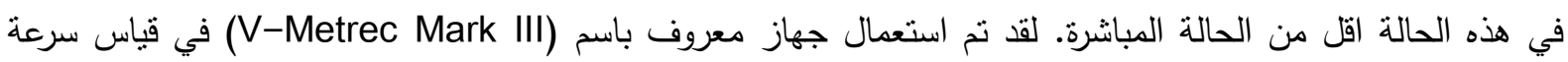
الموجات فوق الصوتية وبالطريقة المباشرة (أي وضع المرسل والمستقبل على وجهين متقابلين من أوجه النموذج المراد

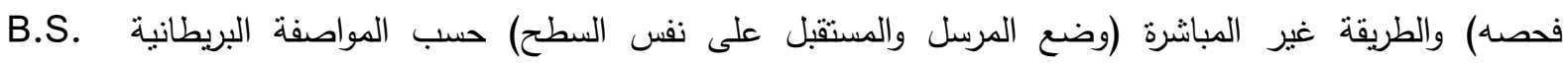

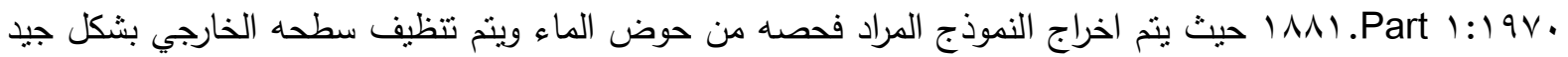
وقياس طول مسار الموجة بدقة ويثبت هذا الطول بالجهاز ويتم تزييت منطقة تلامس المرسل والمسنقبل مع سطح النموذج بواسطة زيت التشحيم وذللك لغرض سد الفجوات الموجودة على سطح النموذج وقبل إجراء الفحص تتم معايرة للجهاز

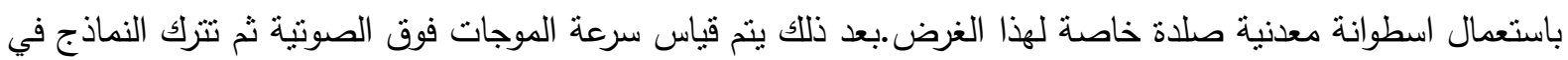
المختبر وذللك لغرض إجراء عملية الحرق عليها. 
يفضل تفادي حديد التسليح إذا أمكن حيث ان له تأثثر في زيادة سرعة النبضات (سرعة النبضات في الحديد 90,9 9 /ث) هذا وتوجد حالتين لوضع حديد النسليح بالنسبة لخط سريان النبضات. الحالة الأولى: ان يكون محور السيخ عمودياً على مسار النبضات وفي هذه الحالة تتأثر القراءات بقطم الاسياخ التي تعترض مسارها ويتم تطبيق معامل تصحيح يعتمد على قطر الاسياخ. الحالة الثانية: عندما يكون محور السيخ موازي لخط السريان وفي هذه الحالة تخرج أول موجة و تتجه لتسير خلال السيخ

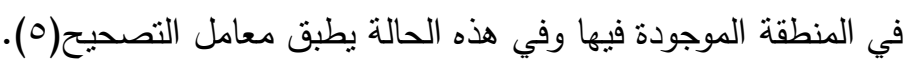

ـ - r مطرقة شميت

تستخدم مطرقة شميت لتعيين رقم الارتداد حيث يعتمد عمل الجهاز على النظرية التي تتص على ان قوة ارتداد كتلة مرنة بعتمد على قوة السطح الذي تصطدم به ويستخدم رقم الارتداد هذا في الاسترشاد عن القيمة التقريبية لمقاومة

الضغط للخرسانة (0).

1-ينظف مكان اخذ الضربات بسطح · ا× • اسم بواسطة الحجر الموجود مع الجهاز • ب-تيم دق ه اضربة في منتصف القطاع وبعيدا عن اماكن التسليح ويكون اتجاه الضربات عمودي على السطح وطبقا للمواصفة الامريكية ، ASTM C-1 يؤخذ منتسط اكبر عدد من القراءات بحيث لا يزيد الفرق بين اصغرها واكبرها عن V، · وتستبعد القراءات التي لاتستوفي هذا الثرط.

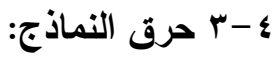

تم استخدام مصدر حراري (عبارة عن رأس مخروطي تتصل به انبوبة مطاطية ومن الجهة الأخرى للأنبوبة يوجد منظم يتصل بانبوبة غاز) في حرق النماذج وتمت عملية الحرق بوضع النموذج الذي على شكل سقق (Slab) على عدد من المكعبات بحيث تكون المكعبات في طرف السقف وتكون من ثلاث جهات ويتم ادخال المصدر الحراري من الجهة الرابعة إلى داخل التجويف المتكون وبهذا تسلط النار مباشرة على النماذج ويتم قياس درجة الحرارة التي يصل إليها النموذج باستخدام محرار ليزري (محّسُ الليزر يقيس اشعاع الحرارة المبعوث ويقوم بعكسه ونقله إلى الدحرار وبذلك دئك

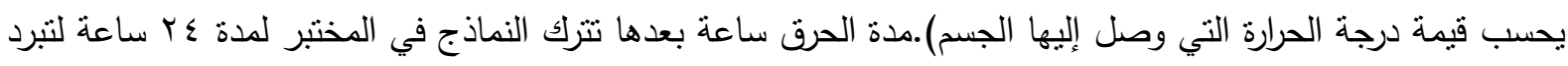
ثم يتم فحصها مرة ثانية باستخدام جهاز (V-Metrec Mark III) ومطرقة شميت ليتم تقييمها بعد الحرق. ؟ - ؛ اكتشاف الثروخ أو الفجوات:

تعتمد فكرة استخدام الجهاز في اكتثاف الثروخ والفجوات على حقيقة ان النبضات لا تسري في الفراغ فتسلك

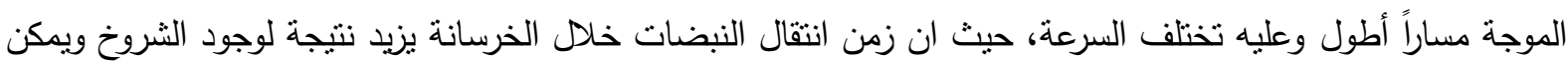

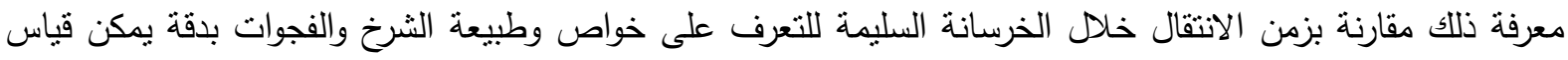
عمق الثرخ تقريباً. ع -ه تحديد درجة تلف الخرسانة: 
تستعمل الموجات في التعرف على درجة تلف الخرسانة من نأثير الحرق وعوامل كيميائية أو ميكانيكية وذلك بتحديد سرعة الموجات بالأجزاء السليمة من الجزء الإنشائي واعتبار ان سرعة انتقال الموجة خلال الطبقة التالفة مساوياً للصفر وتحسب عمق الطبقة التالفة من المعادلة:

$$
d=\frac{x_{0}}{2} \sqrt{\frac{V_{2}-V_{1}}{V_{2}+V_{1}}}
$$

عمق الطبقة التالفة (mm) ع (m)

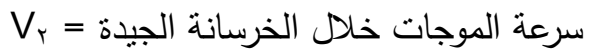

V, Vرعة الموجات خلال الخرسانة الضعيفة

x.=المسافة التي يحدث خلالها التغير في الميل والمترافقة مع سرعتين مختلفتين خلال الخرسانة

\section{0 - n - n مناقشة النتائج:}

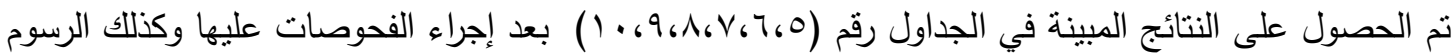

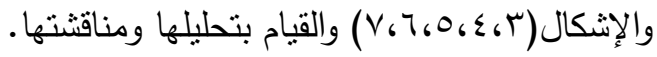

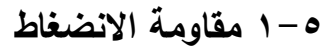

تعتبر مقاومة الانضغاط من أهم خصائص الخرسانة في حالتها المتصلبة وهي مؤشر مهم في تحديد نوعية الخرسانة عند تعرض الخرسانة إلى مستويات عالية من درجات الحرارة، يتأثر سلوكها بشكل عام ومن ابرز مظاهر هذا فها

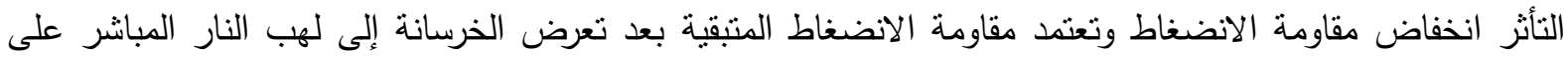

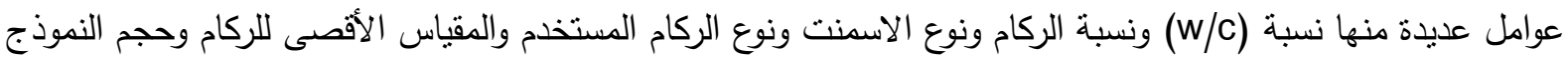
وشكله وظروف المعالجة مضاف إليه مقاومة الخرسانة ودرجة حرارة التسخين وفترة التسخين.

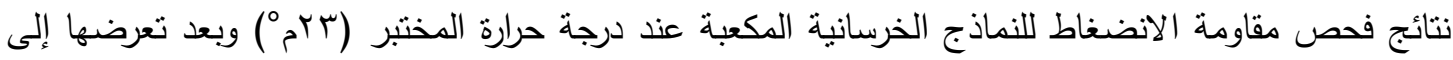

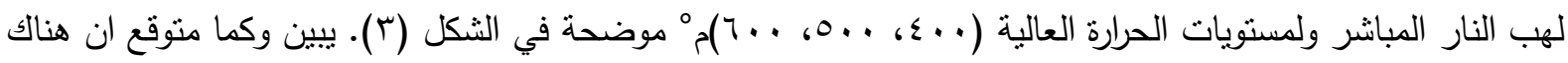

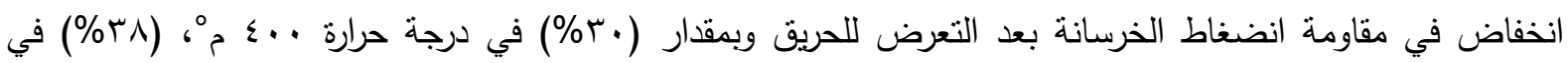

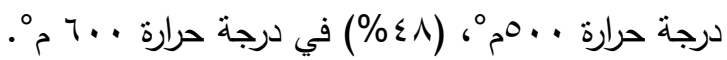

ان الفقدان الحاصل في مقاومة الانضغاط وبنسب مختلفة يعود إلى سلسلة معقدة من الظواهر الكيمياوية و

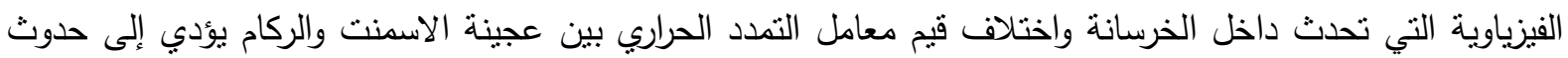
اجهادات على سطح التماس بينهما والتي تعتبر منطقة حرجة وتؤثر بشكل واضح على أداء الخرسانة عند تعرضها لارجات الحرارة العالية حيث تعمل هذه الاجهادات على تمزيق قوى الربط وإضعاف المقاومة، في الوقت نفسه يحدث فقدان للرطوبة وتوليد متصاعد لضغط البخار الداخلي ترافقه تغيرات كيمياوية لعجينة الاسمنت اهمها تحول هيدروكسيد الكالسيوم Ca(OH)r

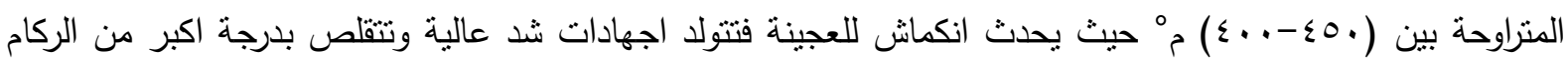
مولدة اجهادات انضغاط في الركام مما يؤدي إلى ضعف في قوى الربط رمن جهة أخرى فإن تبريد الخرسانة المسخنة 
لتصل درجة حرارتها إلى درجة حرارة المحيط يساهم في خفض مقاومة الخرسانة ايضاً وذلك بسبب اختلاف سرعة التبريد بين سطح النموذج الخرساني وداخله الأمر الذي يسبب نمو الثقوق المتولدة مسبقاً واتساعها.

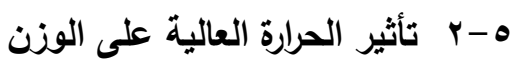

وزن النماذج قبل و بعد التعرض للحريق تم تحديده وفق الالية المشار اليها في البرنامج العملي. و تم احتساب الفقدان في

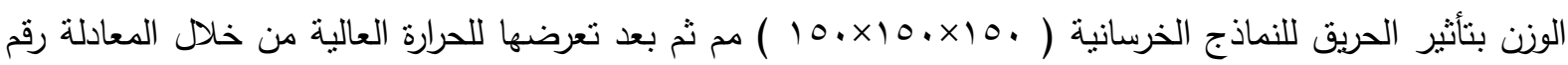

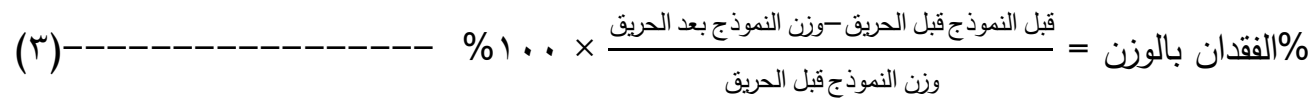

الخرسانة مادة مسامبة تحنوي على مسامات دقيقة و مرتبطة او غير مرتبطة مختلفة الاحجام و الاشكال و يطلق

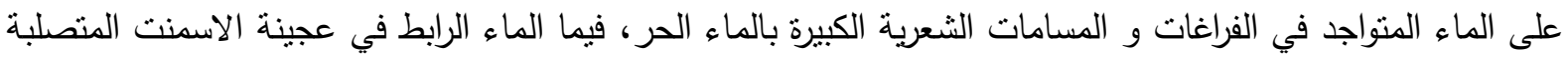
فيطلق عليه بماء الربط او ماء التميؤ و يعتبر بحالة ثابتة جدا و يمكن ان يزال عند درجات الحرارة المتجاوزة (. (1)

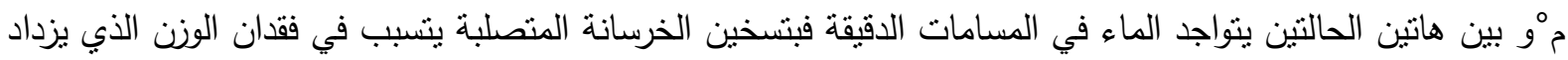

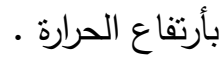

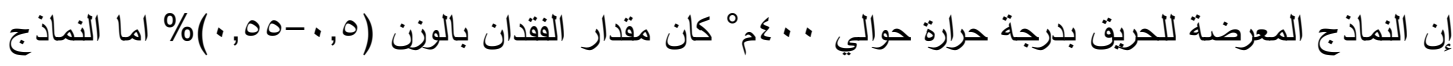

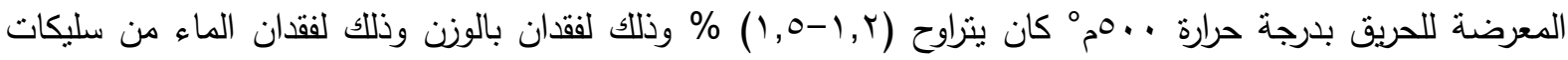

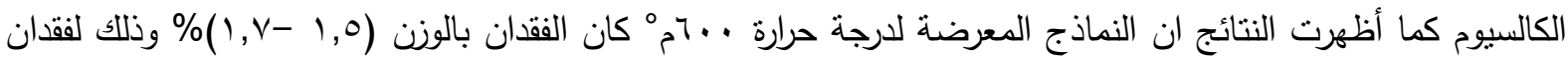

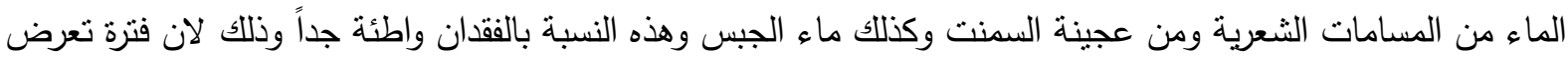
النماذج للحريق كانت قليلة.

هذه النتائج المستحصلة من البحث كانت واطئة عند مقارنتها مع النتائج من البحوث السابقة والمعرضة للحرق بالفرن وذلك لان التعرض إلى لهب النار يكون سطحي مقارنة مع الحرق بالفرن (حرق متجانس) كما مبين في جدول رقم

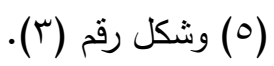

\section{ه- r ت تأثير الحريق على الفحوصات اللااتلافية}

\section{ه-r-1 فحص الموجات فوق الصوتية}

هذه التقنية واسعة الاستعمال في تقييم مدى تجانس الخرسانة وان سرعة الموجات فوق الصونية للنماذج الخرسانيه المعدة في هذا البحث موضحة في الجدول (؟) قبل الحرق وفي الجدول(V) بعد الحرق وشكل (ع). ان مقدار الانخفاض في سرعة الموجات فوق الصوتية وللنماذج الخرسانية المعرضة الى لهب النار بدرجة حرارة حوالي . . عم مكان

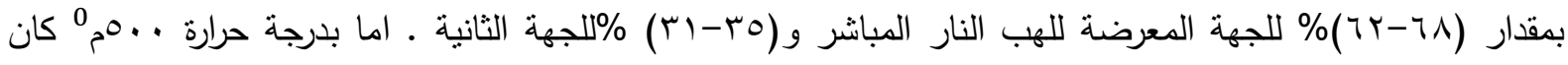

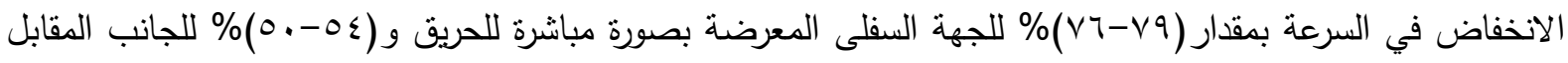

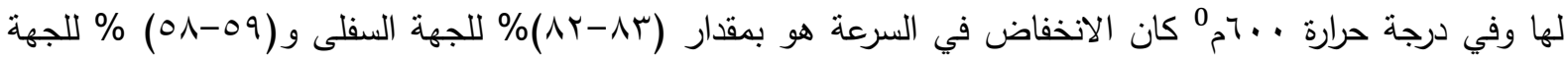
المقابلة لها وان مقدار الانخفاض في سرعة الموجات فوق الصوتية والمستحصلة من البحث تتوافق مع نتائج البحوث

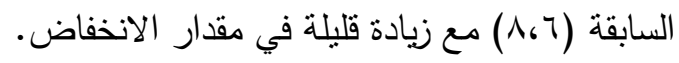


تستخدم مطرقه شميدت لتعيين رقم الارتداد rebound number حيت يعتمد عمل الجهاز على النظريه التي تتص على ان قوة ارتداد كتله مرنه يعتمد على قوة السطح الذي تصدم به ويستخدم رقم الارتداد في الاسترشاد عن القيمه

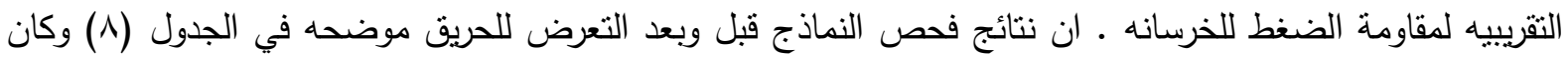

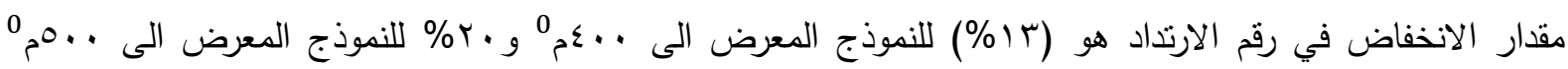

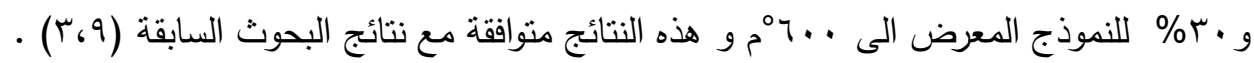
ه- - تحديل سمك الطبقة التالفة:

للتعرف على درجة تلف الخرسانة الناتج من ثاثير الحريق او غيرها من العوامل عندئذ بمكن تحديد هذه المناطق

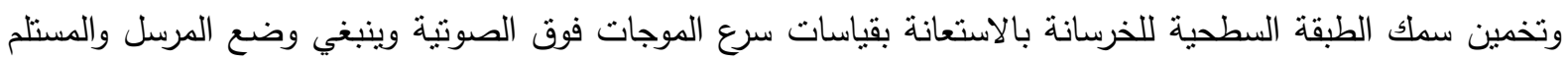
عند مواقع متعددة وتسجيل الازمان المستحصلة ثم رسم العلاقة بين الزمن المستحصل وبين المسافة ويعتمد على المستقيم الذي يعطي افضل ارتباط وهكذا كلما تكون المسافة اقصر بين المجسات سنكون الموجة اكتر انتقالا عبر السطح ثم بعد مسافة معينة ستكون الموجات المنتقلة خلال الخرسانة قد مرت خلد الطبقة السفلى للخرسانة حتى تصل الى الطبقة السفلى للخرسانة حتى تصل الى الطبقة الاجود نوعية بحيث يكون الميل المستحصل مختلفا عن الميل الاولي. فاذا فرضنا (Xo) هي المسافة التي يحدث خلالها التغيير في الميلان والمترافقة مع سرعتين مختلفتين للموجات خلال الخرسانة ولنفرض ان السرعة خلا الخرسانة الضعيفة V) والسرعة خلال الخرسانة الجيدة عr عندئذ يمكن تحديد سمك الطبقة التالفة من المعادلة (r). وقد تم تحديد سمك الطبقة التالفة للنماذج الخرسانية المستخدمة في البحث وكانت النتائج موضحة في الثنكل

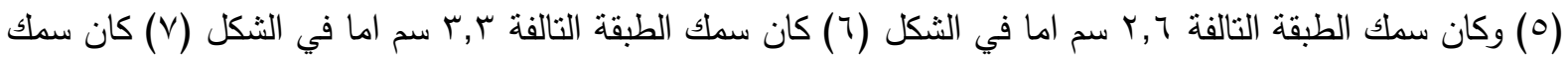
الطبقة التالفة م,ء سم. ه-ه استخدام المعادلة المشتركة بين رقم الارتداد و سرعة الموجات فوق الصوتية في تخمين مقاومة الانضغاط للنماذج قبل و بعد الحرق (•) : المعادلة المستخدمة لايجاد مقاومة الانضغاط:

$\mathrm{C}=\cdot, q \mu \mathrm{R}^{\wedge} \cdot, \tau r \operatorname{EXP}(\cdot, r, U)$ $[r]$

R: رقم الارتداد

C:(MPA) مقاومة الانضغاط

U: (SEC/KM) سرعة الموجات

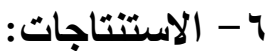

ا - تقل مقاومة الانضغاط عند تعرض الخرسانة الى لهب النار وبمقدار (•r\%) للنماذج المعرضة للهب نار بمقدار

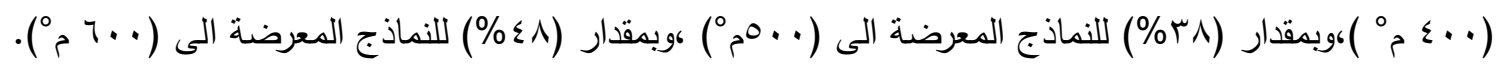
r- بزداد الفقدان في وزن النماذج مع ارتفاع درجة الحرارة. 


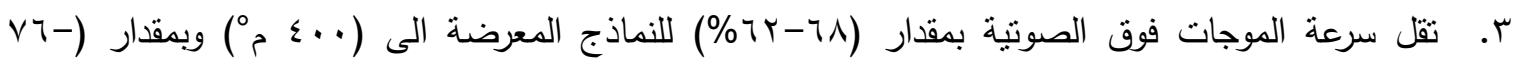

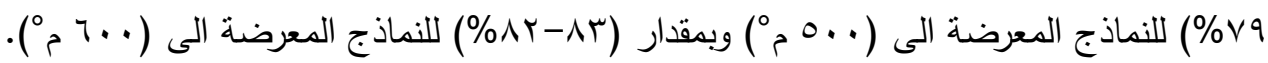

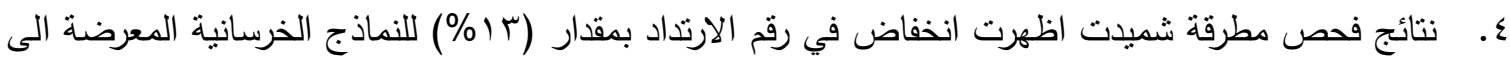

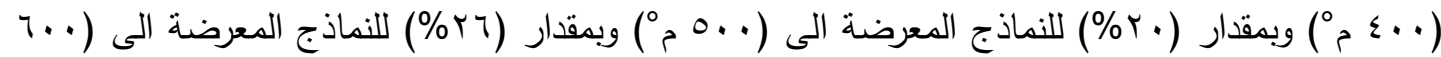

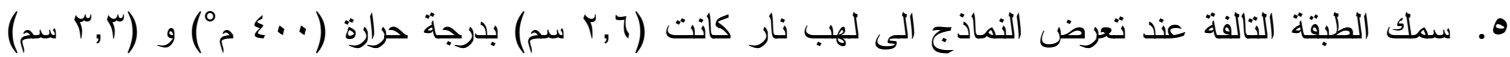

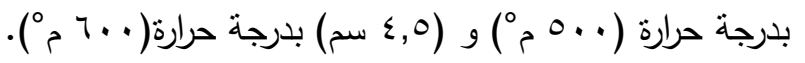

: المصادر - V

1 - حمدي الديداموني، محمد هيكل "تاثير الاضافات (البوزولانية) على مقاومة الخرسانة لدرجات الحرارة العالية".

r. Zoldener, N.G (। १४\) "thermal properties of concrete".

r. Essa M.S. (1999) "effect of burning by fire flame on properties of concrete"

£. Devenny (191•) "the effect of temperature on the compressive strength of concrete" هـ الفحوص الغير اتلافية للخرسانة ـدائرة البحوث و الثوون الفنية "د.مفيد عبد الو هاب ,د.د.لامع عبد المجيد ,م.يوسف كلو

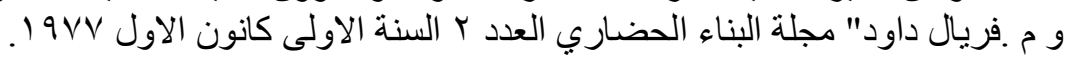

7. Chung h. w (1910)"Ultrasonic testing of concrete after exposing to high temperature".

$\checkmark$. Umran, m. k ( $\ldots, r)$ "fire flame exposure effect on some mechanical properties of concrete".

^. Logothetis, L. and Economou, chr, (1911)"The influence of high temperature on calibration of non-destructive testing of concrete".

9. Chung. H. W. and- Law, K .S. "Assessing fire damage of concrete by ultrasonic pulse technique".

1.- ASTM Cr10 - r..r,Standard Test Method for Fundamental Transfer, Longitudinal and Tensional Resonant Frequency of concrete Specimens Annual Book of ASTM Standard vol. $\varepsilon, r, r \cdots r$, pp. ${ }^{\prime}-r$.

جدول (1): بيين الخلطة التصميمية.

\begin{tabular}{|c||c||c|c|c|}
\hline $\begin{array}{c}\text { Cement } \\
\mathrm{kg} / \mathrm{m}^{r}\end{array}$ & W/C ratio & $\begin{array}{c}\text { Coarse agg, } \\
\mathrm{kg} / \mathrm{m}^{r}\end{array}$ & $\begin{array}{c}\text { Fine agg. } \\
\mathrm{kg} / \mathrm{m}^{r}\end{array}$ & $\begin{array}{c}\text { Water } \\
\mathrm{kg} / \mathrm{m}^{r}\end{array}$ \\
\hline \hline$\varepsilon \circ \mathrm{OV}$ & $\cdot, \varepsilon r$ & 90. & $77 r, 70$ & $191,9 \varepsilon$ \\
\hline
\end{tabular}




$$
\text { جلول (ץ): يبين تدرج الركام الخشن. }
$$

\begin{tabular}{|c|c|c|}
\hline 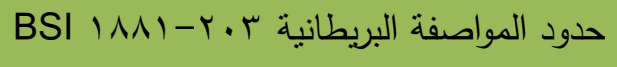 & النتائج & نوع الفحص الركام الخشن \\
\hline 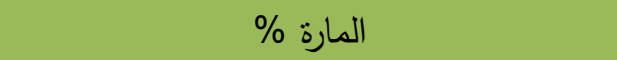 & 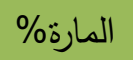 & حجم المنخل mm \\
\hline $1 \ldots$ & $1 \ldots$ & $r v, 0$ \\
\hline $9 \cdot-1 \ldots$ & 9. & r. \\
\hline$\varepsilon \cdot-\Lambda$. & «o & $1 \leqslant$ \\
\hline$r \cdot-r \cdot$ & ro & 1. \\
\hline.-1 & r & 0 \\
\hline لا يزيد عن ا, ••\% & صفر & SO SO SO \\
\hline
\end{tabular}

جدول (ץ) : يبين ندرج الركام الناعم.

\begin{tabular}{|c|c|c|}
\hline حدود المواصفة البريطانية - حئ & النتائج & التدرج \\
\hline المارة\% & المارة\%\% & مقياس المنخل (ملم) \\
\hline $1 \ldots$ & $1 \ldots$ & 1. \\
\hline$\wedge q-1 \ldots$ & 9. & $\varepsilon, \vee_{0}$ \\
\hline $70-1 \ldots$ & $7 \varepsilon$ & דו \\
\hline$\varepsilon 0-1 \ldots$ & or & 1,11 \\
\hline ro-ᄉ. & or & $\cdot, 7$ \\
\hline $0-\varepsilon \wedge$ & r. & $\cdot r$ \\
\hline.-10 & $\wedge$ & $\cdot, 10$ \\
\hline
\end{tabular}

جدول (ع ): يبين نتائج فحص الاسمنت.

\begin{tabular}{|c|c|}
\hline 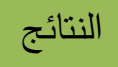 & الفحوصات الفيزيائية \\
\hline 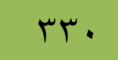 & Kg/m² النعومة \\
\hline$r: .0$ & وقت التماسك الابتدائي (دقيقة: ساعة) \\
\hline $0: .0$ & وقت التماسك النهائي (دقيقة: ساعة) \\
\hline$\cdot, \cdot r$ & السلامة (الثبات) بطريقة المحمم (\%) \\
\hline النتائج & الفحوصات الكيميائية \\
\hline $7 \cdot, 0$ & $(\%) \mathrm{CaO}$ \\
\hline
\end{tabular}


تقييم سمك الطبقة التالفة لنماذج خرسانية مسلحة معرضة للحريق

\begin{tabular}{|c|c|}
\hline ru,ro & $(\%) \mathrm{SiO}_{r}$ \\
\hline $0, \pi$ & $(\%) \mathrm{Al}_{r} \mathrm{O}_{r}$ \\
\hline r & $(\%) \mathrm{Fe}_{r} \mathrm{O}_{r}$ \\
\hline$\cdot, \wedge 7$ & معامل الاثباع الجيري \\
\hline r & $\% \mathrm{MgO}$ \\
\hline T,YV & محتوى ro(\%) \\
\hline$r, 9$ & الفقدان بالحرق (\%) \\
\hline $1, r 7$ & المواد الغير قابلة للذوبان (\%) \\
\hline $1 \cdot, 1 T$ & $(\%) \mathrm{C}_{r} \mathrm{~A}$ \\
\hline- & $(\%) \mathrm{C}_{r} \mathrm{~S}$ \\
\hline- & $(\%) \mathrm{C}_{Y} \mathrm{~S}$ \\
\hline- & $\mathrm{C}_{\varepsilon} \mathrm{AF}$ \\
\hline- & $\mathrm{Fe}_{r} \mathrm{O}_{r}-\mathrm{Al}_{r} \mathrm{O}_{r}$ \\
\hline النتائج & تحمل الضغط \\
\hline 11,9 & بعمر (r) أيام \\
\hline$r \leqslant, 9$ & بعمر (V) أيام \\
\hline
\end{tabular}

جدول (•): يبين الفقدان في الوزن للنماذج المكعبة المعدة في هذا البحث تحت نأثير الحرارة العالية.

\begin{tabular}{|c|c|c|c|}
\hline اللوزن بعد التعرض (كغم) & الوزن قبل التعرض للحريق (كغم) & رقم النموذج & درجة حرارة الحريق (مº) \\
\hline$\Lambda, \ldots r$ & $\Lambda, \cdot \leq \varepsilon$ & 1 & \multirow[t]{3}{*}{$\varepsilon \ldots$} \\
\hline$\wedge, \cdot \perp \vee$ & $\Lambda, \cdot T r$ & r & \\
\hline$\Lambda, \cdot 1 \Gamma$ & $\wedge, .07$ & r & \\
\hline$\vee, \wedge . \diamond$ & $\vee, \wedge \wedge \leq$ & $\varepsilon$ & \multirow[t]{3}{*}{$0 .}$. \\
\hline$V, 797$ & V,Ar० & 0 & \\
\hline$\vee, 797$ & $\vee, \vee q$. & 7 & \\
\hline V,Ar. & $v, 90$. & V & \multirow[t]{3}{*}{7.} \\
\hline$\vee, \wedge \circ \leq$ & $\vee, 99$. & $\wedge$ & \\
\hline$V, V \vee r$ & $\vee, q$. & 9 & \\
\hline
\end{tabular}


جدول (†): يبين سرعة الموجات فوق الصوتية قبل الحرق (m/sec).

\begin{tabular}{|c|c|c|c|c|c|}
\hline$r$ & r & 1 & \multicolumn{3}{|c|}{ رقم النموذج } \\
\hline سTr & sov. & $\{011$ & \multicolumn{2}{|c|}{ عمودي على التسليح } & \multirow{2}{*}{ فحص مباشر } \\
\hline$\sum 070$ & ETro & ¿०VT & \multicolumn{2}{|c|}{ موازي إلى النسليح } & \\
\hline rی.v & $\varepsilon r \cdot 1$ & rq. $\varepsilon$ & عمودي على التسليح & \multirow{2}{*}{ الجهة السفلى } & \multirow{2}{*}{ فحص غير مباشر } \\
\hline raor & $\varepsilon \cdot r$ & $\varepsilon \cdot r V$ & منوازي إلى التسليح & & \\
\hline r^.. & एवтร & ऍ^я. & عمودي على التسليح & \multirow{2}{*}{ للجهة العليا } & \multirow[b]{2}{*}{ فحص غير مباشر } \\
\hline rAYt & TVYT & rev. & موازي إلى التسليح & & \\
\hline
\end{tabular}

جدول (v): سرعة الموجات فوق الصوتية بعد عملية الحرق(ces/m).

\begin{tabular}{|c|c|c|c|c|c|}
\hline$r$ & r & 1 & \multicolumn{3}{|c|}{ رقم النموذج } \\
\hline $7 \ldots$ & $0 .$. & $\varepsilon \ldots$ & \multicolumn{3}{|c|}{ درجة الحرارة (مº) } \\
\hline $17 \cdot r$ & 1719 & $r Y \cdot r$ & \multicolumn{2}{|c|}{ عمودي على التسليح } & \\
\hline $1 \cdot \varepsilon \varepsilon$ & INr. & 1199 & \multicolumn{2}{|c|}{ موازي إلى التسليح } & فحص مباشر \\
\hline $7 r \wedge, \wedge$ & $1 \cdot r \varepsilon$ & $1 \leqslant 94$ & عمودي على التسليح & \multirow{2}{*}{ الجهة السفلى } & فحص غبر \\
\hline VIr & NHY & $|r q|$ & متوازي إلى التسليح & & مباشر \\
\hline 100 & $|\wedge \varepsilon|$ & rork & عمودي على التسليح & الجهة العليا & فحص غير \\
\hline $17 \ldots$ & $1 \wedge 7$. & rq.. & موازي إلى التسليح & 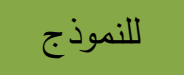 & 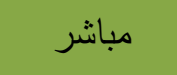 \\
\hline
\end{tabular}

جدول رقم (^): يبين رقم الارتداد قبل وبعد الحرق.

\begin{tabular}{|c|c|c|}
\hline رقم الارتداد بعد الحرق & رقم الارتداد قبل الحرق & رقم النموذج \\
\hline 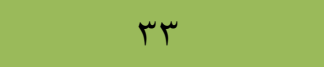 & rᄉ & نموذج (1) تعرض إلى . . عم \\
\hline rt & $\varepsilon$. & نموذج (Y) تعرض إلى . . ممْ \\
\hline r & $\varepsilon \varepsilon$ & نموذج (r) تعرض إلى . . بحمْ \\
\hline
\end{tabular}


تقييم سمك الطبقة التالفة لنماذج خرسانية مسلحة معرضة للحريق

جدول رقم (9): يبين مقاومة الانضغاط باستخدام رقم الارتداد.

\begin{tabular}{|c|c|c|}
\hline مقاومة الاتضغاط بعد الحرق & مقاومة الانضغاط قبل الحرق & رقم النموذج \\
\hline$r V, r$ & $\varepsilon r, 0$ & نموذج (1) تعرض الى · . عمْ \\
\hline ro,r & $\leqslant 7$ & نموذج (Y) تعرض الى . . ممْ \\
\hline$r \varepsilon, 7$ & 01,0 & نموذج (r) تعرض الى . . آمْ \\
\hline
\end{tabular}

جدول (• 1): تخمين مقاومة الانضغاط قبل و بعد الحرق باستخدام رقم الارتداد و سرعة الموجات فوق الصوتية.

\begin{tabular}{|c|c|c|}
\hline مقاومة الانضغاط بعد الحرق & مقاومة الاتضغاط قبل الحرق & رقم النموذج \\
\hline Ir & $\Gamma \cdot, \wedge$ & 1 \\
\hline זr,ו & $r \varepsilon, \wedge$ & r \\
\hline $9, \wedge 7$ & $M r, \Lambda$ & $r$ \\
\hline
\end{tabular}

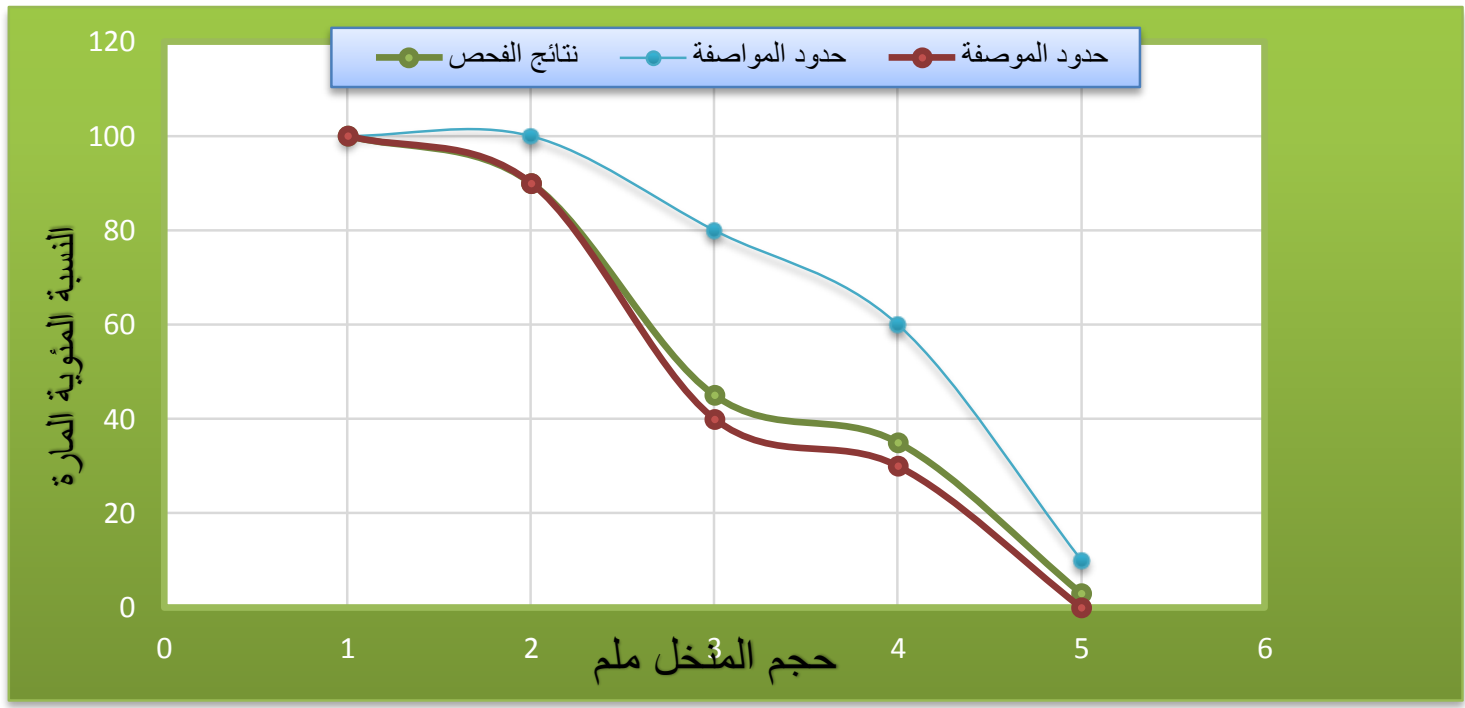

شكل( (1): التحليل المختبري للركام الخشن مقلع المقدادية. 
تقييم سمك الطبقة التالفة لنماذج خرسانية مسلحة معرضة للحريق

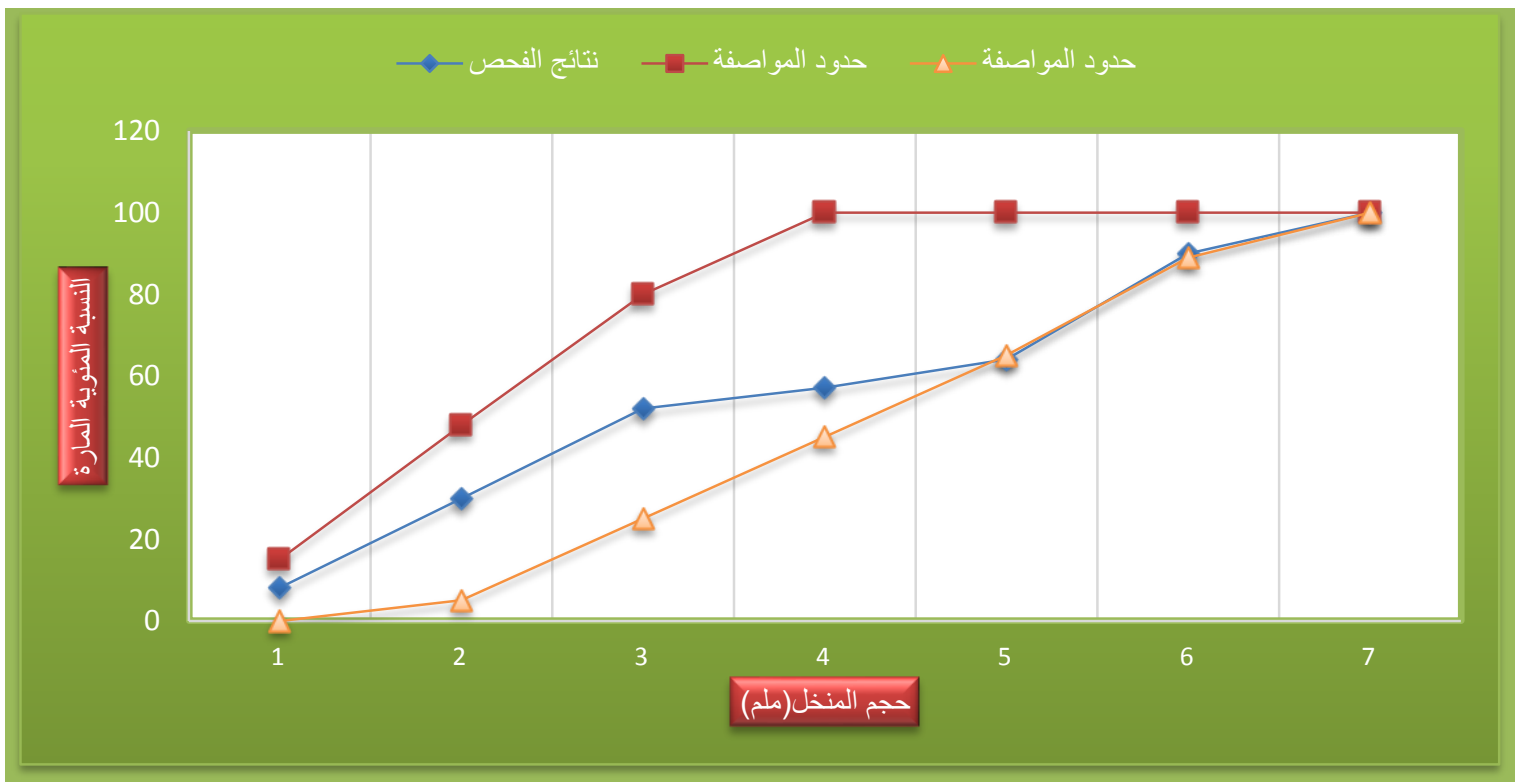

شكل (ץ): يبين التحليل المنظلي للركام الناعم.

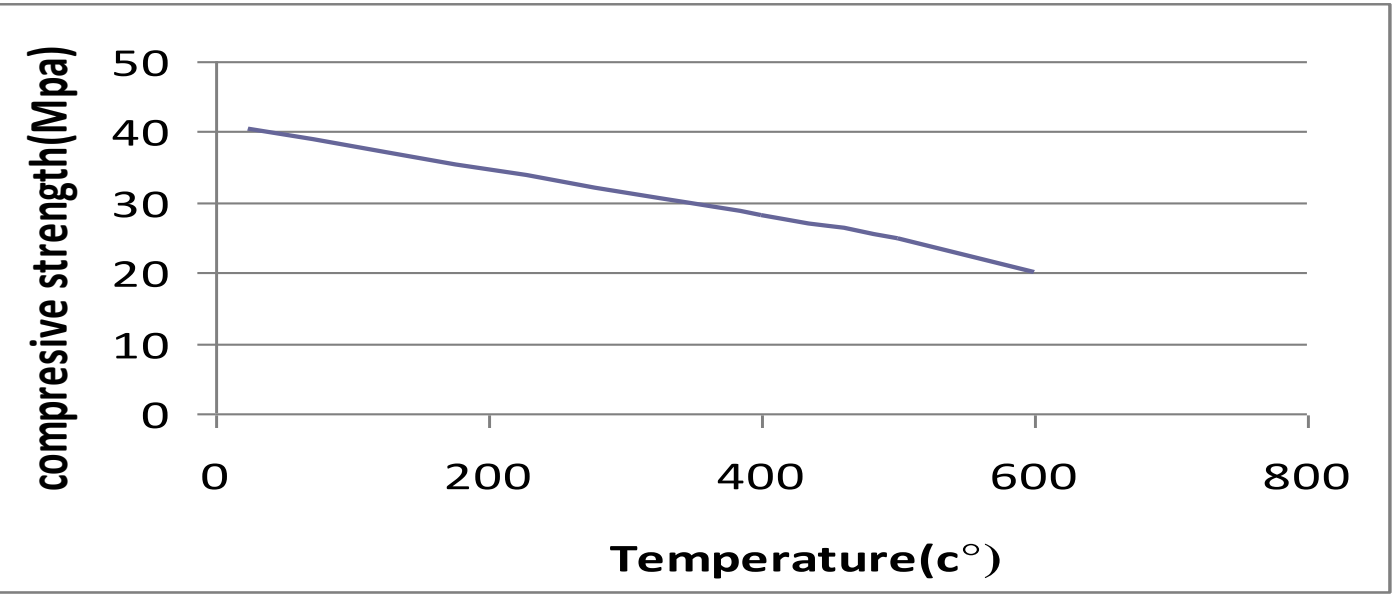

الثكل (ץ): مقاومة الانضغاط تحت ثأثثير درجات الحرارة العالية.

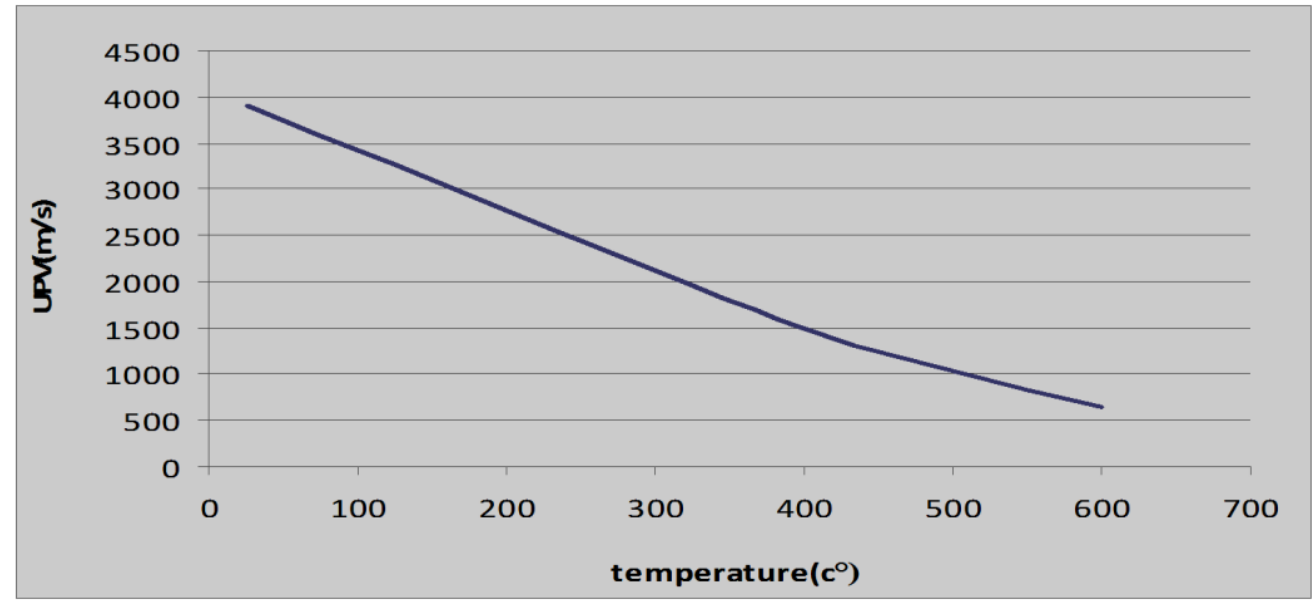

الشكل (؛): تأثنر الحريق على سرعة الموجات فوق الصوتية. 
تقييم سمك الطبقة التالفة لنماذج خرسانية مسلحة معرضة للحريق

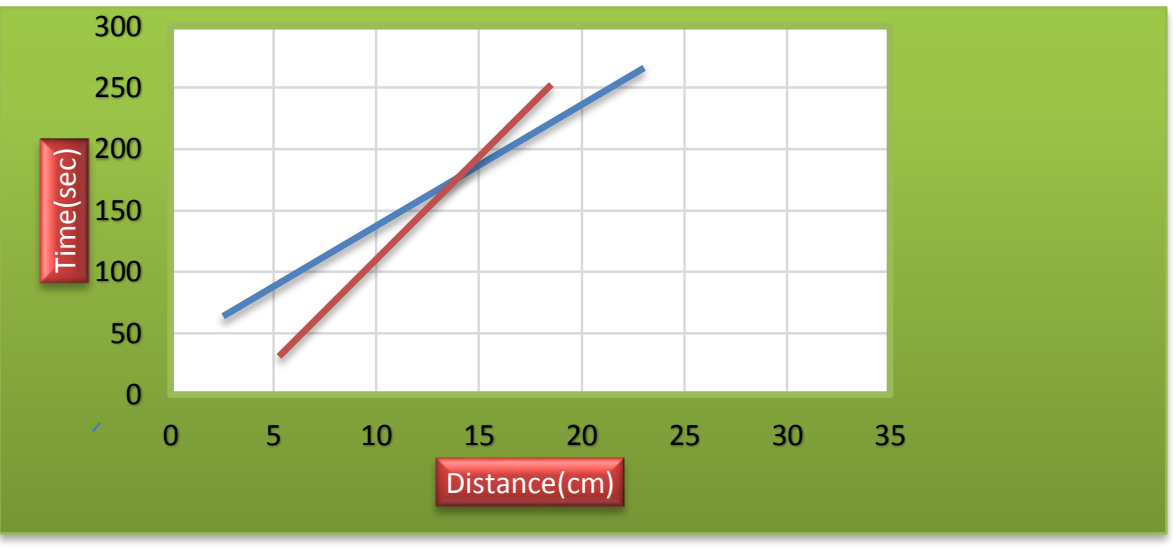

الشكل(ه): استخدام الطريقة السطحية للسرعات فوق الصوتية لتحديد سمك الطبقة التالفة لنموذج معرض الى ..ـ مْ

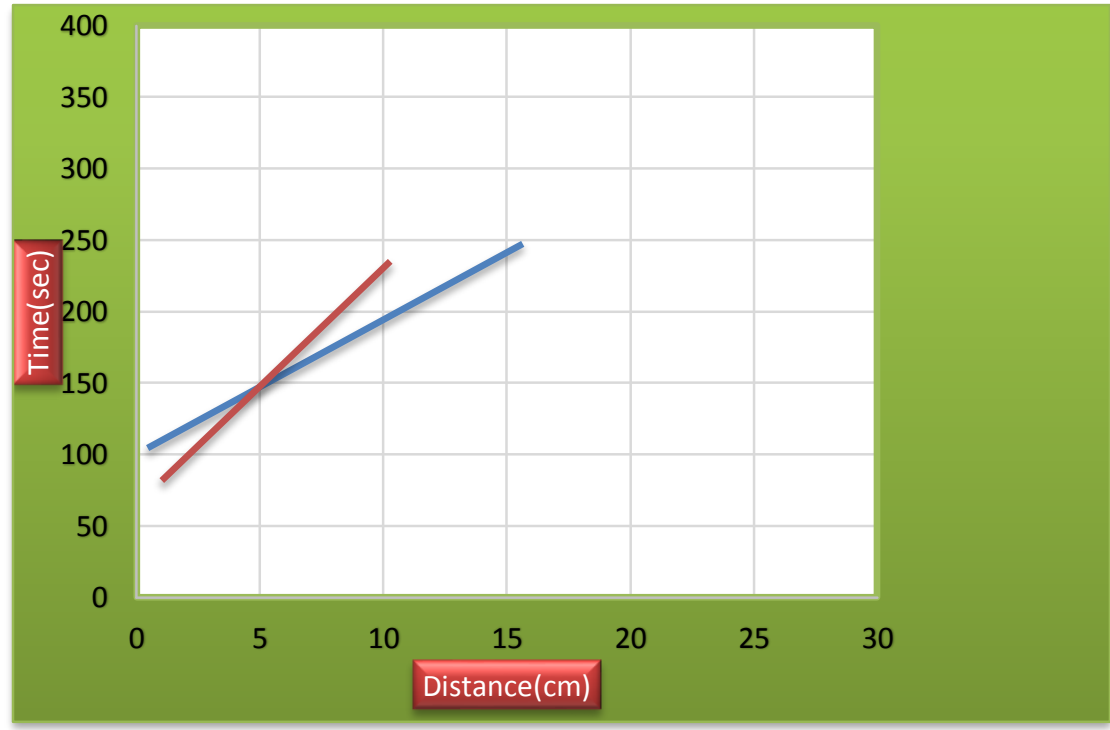

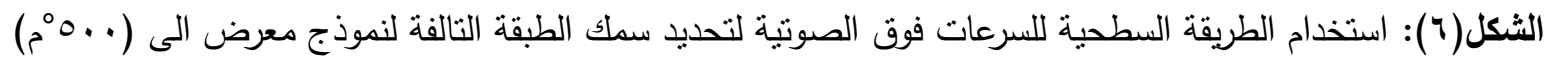

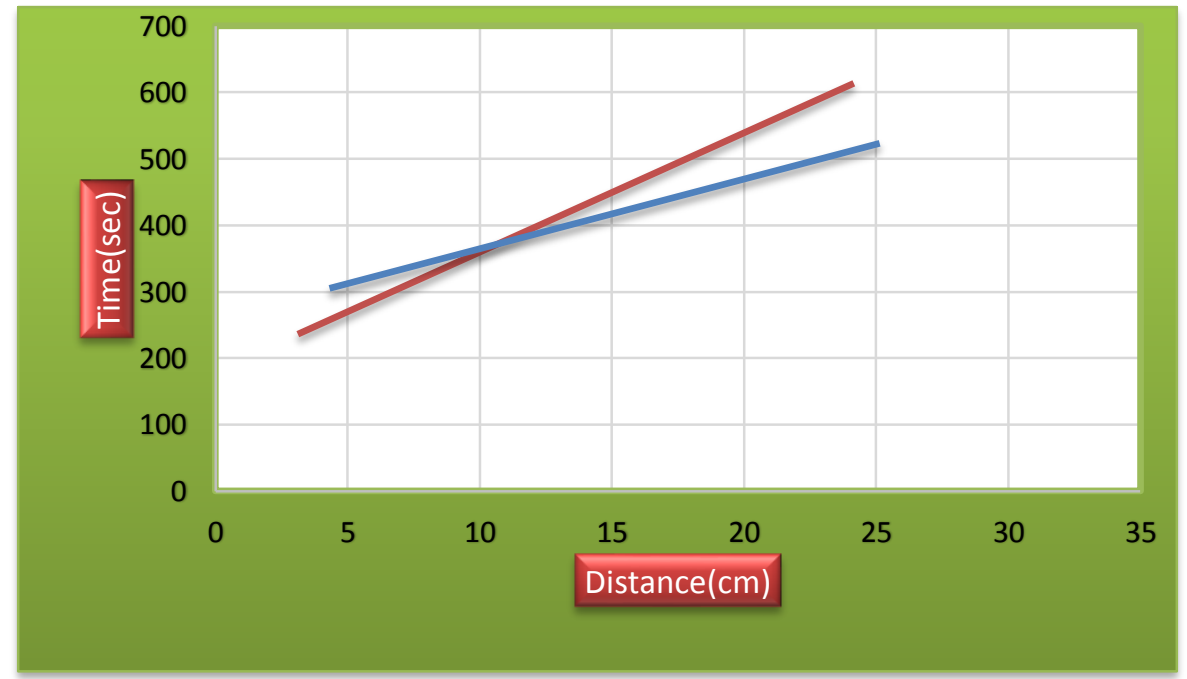

الثكل(V): استخدام الطريقة السطحية للسرعات فوق الصوتية لتحديد سمك الطبقة التالفة لنموذج معرض الى ( . T مº). 


\title{
EVALUATE THE DEPTH OF DESTROYED LAYER FOR REINFORCEMENT CONCRETE SAMPLES EXPOSED TO FIRE
}

\author{
Safie M. oleiwi \\ College of engineering / Diyala University
}

\begin{abstract}
The behavior of reinforcement concrete slab dimension $\left(0 \cdot x^{0} \cdot x^{10} \cdot\right) \mathrm{mm}$ and the cubes dimension $(10 . x$ 10. $\mathrm{x} 10.) \mathrm{mm}$ samples are evaluated to the effect of fire according to the mix design concrete $\leftleftarrows$ - Mpa compressive strength. The samples are exposited to the direct flame fire from down surface for three level of temperature degree $(\varepsilon \cdots, 0 \cdots$ and $7 \cdots) C^{\circ}$ for one hour. After the samples are cooled to the normal degree of temperature, two non-distractive test are carried out: pulse velocity and shmidt hammer before and after the fire. Also the destroy layer depth is measured for the slab samples after the fire so the samples of cubes are prepared and tested after burning at the same circumstance which appear to slab reinforcement samples are purposed to found the change of the weight ,the compressive strength, pulse velocity and the number of rebound. The results indicate to $(r \cdot \%)$ reducing in compressive strength at level of temperature degree $\leqslant .$. $\mathrm{C}^{\circ}$, and $(\kappa \wedge \%)$ reducing in compressive strength at level of temperature degree $\bullet \cdot \mathrm{C}^{\circ},(\varepsilon \wedge \%)$ reducing in compressive strength at level of temperature degree $7 \cdots \mathrm{C}^{\circ}$. The weight loss appear $\left(\cdot, 0_{-}, 00\right) \%,\left(1, Y_{-}, 0_{0}\right) \%$, and $\left(1,0_{-}, \nu^{\vee}\right) \%$ for three level of temperature degree

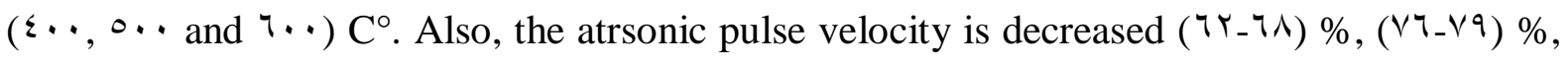

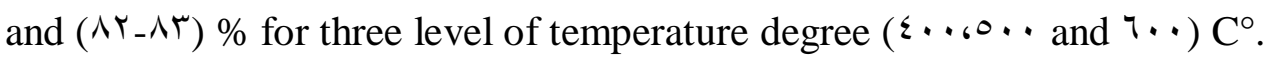

Keyword: concrete samples, degree of high temperature, compressive strength test, nondistractive test. 